\title{
Interaction between childhood adversity and functional polymorphisms in the dopamine pathway on first-episode psychosis
}

Antonella Trotta ${ }^{1,2 \mathbb{I}}$, Conrad Iyegbe ${ }^{3 \mathbb{I}}$, Jenny Yiend ${ }^{3}$, Paola Dazzan ${ }^{3,4}$, Anthony S. David ${ }^{3,4}$, Carmine Pariante ${ }^{4,5}$, Valeria Mondelli ${ }^{4,5}$, Marco Colizzi ${ }^{3}$, Robin M. Murray ${ }^{3,4}$, Marta Di Forti $^{1,4}$, Helen L. Fisher ${ }^{*}$

${ }^{1}$ Social, Genetic \& Developmental Psychiatry Centre, Institute of Psychiatry, Psychology \& Neuroscience, King's College London, London, UK

${ }^{2}$ Heather Close Rehabilitation Service, South London and Maudsley NHS Foundation Trust, London, UK

${ }^{3}$ Department of Psychosis Studies, Institute of Psychiatry, Psychology \& Neuroscience, King's College London, London, UK

${ }^{4}$ National Institute for Health Research (NIHR) Maudsley Biomedical Research Centre at South London and Maudsley NHS Foundation Trust and King's College London, London, UK

${ }^{5}$ Department of Psychological Medicine, Institute of Psychiatry, Psychology \& Neuroscience, King's College London, London, UK

II These authors contributed equally to this work.

* Corresponding author at: SGDP Centre, Institute of Psychiatry, Psychology \& Neuroscience, King's College London, 16 De Crespigny Park, London SE5 8AF, UK. Tel.: +44 2078485430. Fax: +44 2078480866. E-mail address: helen.2.fisher@kcl.ac.uk (H.L. Fisher)

Abstract word count: 250

Main text word count: 3929 


\begin{abstract}
Background: There is consistent evidence of a cumulative relationship between childhood adversity and psychosis, with number of adversities experienced increasing the probability of psychosis onset. It is possible that genetic factors moderate the association between childhood adversity and psychosis, potentially by influencing how an individual reacts biologically and/or psychologically following exposure to adversity, in such a way as to set them off on the path to psychosis. However, identifying the specific genetic variants involved and how they interact with childhood adversity remains challenging. We examined whether the association between cumulative exposure to childhood adversity and development of psychotic disorder was moderated by the COMT Val ${ }^{158}$ Met, AKT1 rs2494732 or DRD2 rs1076560 polymorphisms, known to affect dopamine levels.
\end{abstract}

Methods: Participants were 285 first-presentation psychosis cases and 256 geographicallymatched controls drawn from the Genetics and Psychosis (GAP) study. Childhood adversity was assessed using the Childhood Experience of Care and Abuse Questionnaire (CECA.Q) and blood- and cheek-derived genotype data were collected.

Results: Our findings revealed no main effect of COMT Val ${ }^{158} \mathrm{Met}$, AKT1 rs2494732 and DRD2 rs 1076560 polymorphisms on psychosis case status or reports of childhood adversity. Individuals reporting a history of multiple adversities were more likely to be psychosis patients than controls, regardless of their genetic risk. There was no evidence of candidate genotype by childhood adversity interactions in relation to psychosis onset.

Conclusion: These findings did not provide evidence of a possible role of COMT $\mathrm{Val}^{158} \mathrm{Met}$, AKT1 rs 2494732 or DRD2 rs1076560 genotypes in modifying the association between childhood adversity and onset of psychosis.

Keywords: AKT1, childhood trauma, COMT, DRD2, gene-environment, GxE, schizophrenia 


\section{Introduction}

Exposure to adverse events in childhood is associated with around a 2 to 4 -fold increased risk of psychosis (Morgan \& Gayer-Anderson, 2016). Furthermore, childhood traumatic experiences tend to co-occur such that being exposed to one type of adversity increases the risk of exposure to another, with a cumulative effect of trauma on psychosis (Shevlin et al., 2008).

However, very little is known about how exposure to childhood adversity is translated into biological risk for psychosis. One possibility is a gene-environment interaction, whereby a pre-existing genetic vulnerability modifies the biological response to adverse childhood experiences leading to the development of psychotic symptoms. We have previously explored whether genetic susceptibility to psychosis (via family history of psychosis and a polygenic risk score for schizophrenia) interacts with reported exposure to childhood adversity to predict onset of psychotic disorders but did not find any evidence for this (Trotta et al., 2015, 2016). Here we consider whether functionally-relevant polymorphisms might interact with adverse childhood experiences to lead to the development of psychosis. Specifically, dysregulation of the dopamine system has been found among individuals exposed to childhood adversity (De Bellis et al., 1999; Gerra et al., 2007; Heim et al., 2000; Pruessner et al., 2004) and is also postulated to be important in the pathogenesis of psychosis (Howes et al., 2009, 2017; Kapur, 2003; Moore et al., 1999; Spitzer, 1995; Walker \& Diforio, 1997; Walker et al., 2008). Therefore, genes involved in the regulation of dopamine levels in the brain would be plausible biological candidates for interaction with childhood adversity. Indeed several such genes, including Catechol-O-methyltransferase (COMT), AKT1 and the dopamine receptor type 2 (DRD2), have been linked with psychosis (Bolog et al., 2012; Cheng et al., 2006; Egan et al. 2001; Kapur et al., 1999; Karege et al., 2012; Li et al., 1996; Norton et al., 2007; Thiselton et al., 2008). 
The COMT gene plays an important role in the metabolism of dopamine in the central nervous system (Garris et al., 1993). A single nucleotide polymorphism (SNP) in the COMT gene, located on chromosome 22q11.2 (Winqvist et al., 1991), causes an amino acid change from valine to methionine at position 158 ( $\mathrm{Val}^{158} \mathrm{Met}$ ), with a 3- to 4-fold variation in enzymatic activity between $\mathrm{Val} / \mathrm{Val}$ genotype and Met/Met genotype (Chen et al., 2004a; Weinshillboum et al., 1999). Specifically, Met/Met genotype carriers have the lowest COMT activity, whereas the $\mathrm{Val} / \mathrm{Val}$ carriers have the most enzyme activity (Mannisto \& Kaakkola, 1999). Diverse gene-environment interactions have been reported for COMT $\mathrm{Val}^{158} \mathrm{Met}$ in moderating risk for psychotic disorder (Bilder et al., 2004; Tunbridge et al. 2006), for example, in the case of cannabis use in adolescence (Caspi et al., 2005; Henquet et al., 2009) and daily life stress (Peerbooms et al., 2012). Specifically, the Val allele has been associated with self-reported psychotic experiences in the context of stress and cannabis use in a Dutch adult population sample (Vinkers et al., 2013) and with the stress of army induction in a Greek male conscript sample (Stefanis et al., 2007). COMT $\mathrm{Val}^{158} \mathrm{Met}$ has also been associated with increased schizotypal personality trait scores in $\mathrm{Val} / \mathrm{Val}$ individuals exposed to higher levels of childhood trauma (Savitz et al., 2010). Therefore, it seems a relevant candidate gene for testing in interaction with childhood adversity to predict the presence of psychotic disorders.

Another candidate to test for a gene $\mathrm{x}$ childhood adversity interaction is the AKT1 gene, located on chromosome $14 \mathrm{q} 32$, which has been reported to be associated with schizophrenia (Freyberg et al., 2010; Mathur et al., 2010). AKT1 codes for a protein kinase (Protein kinase $\mathrm{B}, \mathrm{PKB}$ ), that forms an integral part of a cascade mediating dopamine signalling in the striatum. Animal and human studies have found that psychosocial stress, including childhood adversity, leads to a sensitization of mesostriatal dopamine neurotransmission, which might increase the risk of developing psychotic symptoms (Egerton 
et al., 2016; Howes et al., 2004). Moreover, a GxE interaction has been reported between an AKT1 gene polymorphism, rs2494732, and an environmental risk factor, cannabis use, in the pathogenesis of psychosis: carriers of the $C / C$ genotype were most likely to develop psychotic illness after smoking cannabis (Di Forti et al., 2012; van Winkel et al., 2011a, 2011b). To date, no studies have investigated an $A K T 1$ gene x childhood adversity interaction in psychosis onset, though a pilot study focusing on the potential relationship of stress and psychosis showed that higher subclinical psychotic experiences were associated with chronic and severe stress and AKT1 rs2494732 in a sample of students (Bruenig et al., 2014).

A third potentially relevant SNP is rs1076560 in the DRD2 gene (chromosome 11q23), located within intron 6, which has been found to be associated with schizophrenia (Ripke et al., 2014). This SNP specifically regulates the expression of the dopamine receptor long (D2L) and short (D2S) isoforms, responsible for dopamine synthesis and release in the frontal cortex (Zhang et al., 2007). In line with previous research on $A K T 1$, the role of the $D R D 2$ gene has only been investigated in the context of the association between cannabis use and psychosis, with subjects carrying the $T$ risk allele showing an increased risk of having a psychotic disorder in the context of cannabis use compared to $G G$ carriers (Colizzi et al., 2015a; 2015b).

We used a first-presentation psychosis case-control sample to investigate whether the association between cumulative exposure to childhood adversity and development of psychotic disorder was moderated by the COMT Val ${ }^{158}$ Met, AKTl rs2494732 and DRD2 rs 1076560 polymorphisms, as these have been shown to be involved in the regulation of dopamine and linked to psychosis. Of the selected candidate genes, only DRD2 elicits genome-wide support for a role in the pathogenesis of schizophrenia (Ripke et al., 2014), although this does not preclude the potential involvement of all three genes in the moderation of childhood adversity, an exposure whose genetic basis has not yet been interrogated on a 
genomic scale. Therefore, we investigated each candidate gene separately in interaction with childhood adversity to explore whether there were specific moderating effects of the selected polymorphisms on the presence of psychotic disorder.

\section{Methods}

\subsection{Sample}

The sample was drawn from first-presentation psychosis cases from the Lambeth, Southwark, Lewisham, and Croydon adult in-patient and out-patient units of the South London \& Maudsley (SLAM) Mental Health National Health Service (NHS) Foundation Trust and unaffected community controls who participated in the Genetics and Psychosis (GAP) study (Di Forti et al, 2015). Participants from this study were included if they had been assessed regarding childhood adversity and provided an analysable sample of DNA. Inclusion criteria for cases were: aged 18-65 years, presenting to psychiatric services for the first time with a psychotic disorder (codes F20-29 and F30-33 from the International Classification of Diseases [ICD-10]; World Health Organization, 1992), and resident within tightly defined catchment areas in Southeast London, UK. Exclusion criteria were: organic psychosis; intelligence quotient (IQ) under 70; previous contact with services for psychosis, and transient psychotic symptoms resulting from acute intoxication.

Controls were aged 18-65 years and recruited from the local population living in the area served by the Trust. Efforts were made to obtain a control sample that was representative of the general population in age, gender, ethnicity, educational qualifications, and employment status. The Psychosis Screening Questionnaire (PSQ; Bebbington and Nayani, 1995) was administered to all potential control group participants; individuals were excluded if they met criteria for a psychotic disorder. 


\subsection{Measures}

\subsubsection{Childhood adversity}

The Childhood Experience of Care and Abuse Questionnaire (CECA.Q; Bifulco et al., 2005) was employed to retrospectively elicit information on a range of adverse childhood experiences from participants. Physical abuse by the main mother and father figures (usually, but not necessarily, the biological parents), sexual abuse by any adult or an individual at least 5 years older than the recipient, separation from a parent for at least 6 months, death of a parent, taken into institutional care, and disrupted family arrangements, all prior to 17 years of age, were assessed. The CECA.Q was read out to all participants during face-to-face interviews to improve the accuracy of the fixed category responses obtained. This questionnaire has been shown to have good internal consistency (Smith et al., 2002), satisfactory levels of test-retest reliability over 7 years in a similar psychosis sample (Fisher et al., 2011), and reasonable concurrent validity with other measures (Bifulco et al., 2005; Fisher et al., 2011; Smith et al., 2002).

\subsection{Genotyping procedures}

Seventy-five percent of DNA samples used originated from blood and $25 \%$ from cheek swabs. A comparison of genotype results for 360 individuals with overlapping blood and cheek swab DNA revealed there was $100 \%$ concordance between blood- and cheekderived genotype data (Di Forti et al., 2015). The DNA was extracted using a standard phenol-chloroform extraction procedure. A Taqman SNP assay was used to genotype the COMT gene at the rs4680 locus, the AKT1 gene at the rs2494732 locus, and DRD2 at the rs1076560 locus (kit format at http://www.appliedbiosystems.com). After an initial Taq polymerase activation/DNA denaturation step, samples were subjected to PCR reaction following standard Applied Biosystem dry DNA protocol. Amplification products were 
analyzed using the Applied Biosystems 7900HT Fast Real-time PCR System. Genotype calls were made based on a clustering algorithm with quality value of $95 \%$.

\subsubsection{Validation of self-reported ethnicity}

To confirm self-report of ethnicity, genetic ancestry was derived using a panel of 57 ancestry informative genetic markers. These were genotyped using iPLEX technology developed for the MassArray platform (Sequenom Inc., San Diego, California) and an ancestry score was derived using the program Structure (Falush et al., 2003) to implement a model-based (Markov Chain Monte Carlo) clustering algorithm. Individuals who scored between $96 \%$ and $100 \%$ for genetic cluster membership were used to create a three-way ancestral axis based on Black African, European Caucasian, and Asian ancestry. These reference groups were used to index genetic ancestry for the remaining sample. Eighty-nine percent of participants had information on both self-reported ethnicity and ancestry markers. The level of overall agreement between self-reported and genetic ethnicities (96\%) was reassuringly high.

\subsection{Ethics}

This study was part of the GAP study, which was granted ethical approval by the South London and Maudsley and Institute of Psychiatry Local Research Ethics Committee (REF: 05/Q0706/158). All cases and controls included in the study gave informed written consent to the publication of data originating from the study.

\subsection{Data analysis}

Data were analyzed using Stata 11 (Stata, College Station, Texas). A composite variable was computed to summarize how many of the different adversities had been 
experienced by each individual, following the guidelines published by Bifulco et al. (2005). This 'total adversity' score involved summing the dichotomous CECA.Q severity subscale scores (range 0-6) and then recoding the total into an ordinal scale of 0 (none), 1 (single adverse experience), and 2 (multiple adverse experiences).

For COMT $\mathrm{Val}^{158} \mathrm{Met}$ polymorphism, the number of $\mathrm{Val}$ alleles and genotypes were coded as 0 (no Val alleles, Met/Met genotype), 1 (one Val allele, Val/Met genotype), and 2 (two Val alleles, Val/Val genotype). The AKT1 gene (rs2494732) was coded as 0 (no risk alleles, $T T$ genotype), 1 (one risk allele, $C / T$ genotype), and 2 (two risk alleles, $C / C$ genotype). The DRD2 gene (rs1076560) was coded as 0 (no risk alleles, $G / G$ genotype), 1 (one risk allele, $G / T$ genotype), and 2 (two risk alleles, $T / T$ genotype).

Cuzick's (1985) non-parametric test of trend for ranks across ordered groups was performed using the 'nptrend' command in STATA to assess associations with psychosis and childhood adversity across the COMT, AKT1 and DRD2 genotypes. This test is considered more sensitive to trends across three or more categories than the standard chi-square test and is also robust to deviations from Hardy Weinberg Equilibrium (HWE) (Cuzick, 1985). The results of this trend test were used to assess the presence of gene-environment correlations between COMT, AKT1, DRD2 genotypes and total childhood adversities in psychosis cases and controls. The main associations and interactions between childhood adversity and COMT, $A K T 1$ and DRD2 genotypes on the presence/absence of psychosis were tested using a generalized linear model with the binomial distribution and identity link function specified (Wacholder, 1986) to estimate risk differences (RD) and 95\% confidence intervals (CI). We tested for interaction with an additive model as it has been argued to be more in line with biological interaction (Knol et al., 2007). All analyses were adjusted for proportion of black genetic ancestry. GxE interaction analyses were conducted firstly with additive genetic models and then using dominant and recessive genetic models for full transparency. COMT 
$\mathrm{Val}^{158} \mathrm{Met}$ genetic models were coded as follows: additive (0=Met/Met, $1=\mathrm{Val} / \mathrm{Met}$, $2=\mathrm{Val} / \mathrm{Val}))$, dominant $(0=\mathrm{Met} / \mathrm{Met}, 1=\mathrm{Val} / \mathrm{Met}$ or $\mathrm{Val} / \mathrm{Val})$, and recessive $(0=\mathrm{Met} / \mathrm{Met}$ or Val/Met, 1=Val/Val). AKT1 rs2494732 genetic models were coded as follows: additive: $(0=T T, 1=C / T, 2=C / C)$, dominant $(0=T T, 1=C / T$ or $C / C)$, and recessive $(0=T T$ or $C / T, 1=C / C)$. DRD2 $r$ s1076560 genetic models were coded as follows: additive: $(0=G / G, 1=G / T, 2=T / T)$, dominant $(0=G / G, 1=G / T$ or $T / T)$, and recessive $(0=G / G$ or $G / T, 1=T / T)$.

\section{Results}

\subsection{Sample characteristics}

Information on number of childhood adversities was available for 285 firstpresentation psychosis patients and 256 unaffected controls. Those who completed the CECA.Q did not differ significantly from non-completers in terms of gender (cases: $\chi^{2}=3.757, \mathrm{p}=0.055 ;$ controls: $\chi^{2}=0.658, \mathrm{p}=0.445$ ), but controls who completed the questionnaire were more often of non-White ethnicity (controls: $\chi^{2}=8.119, p=0.017$ cases: $\left.\chi^{2}=1.368, p=0.500\right)$ and significantly younger than the rest of the GAP sample (controls: mean age 29 vs. 32.8 years, $t=3.183, p=0.002$; cases: $t=-1.705, p=0.089$ ). However, in practice this was only an average of 4 years difference in age which should not have had a significant impact on memory of past events (Fisher et al., 2011).

The demographic characteristics of the sample and the main association between number of childhood adversities in cases and controls are provided in Supplementary Table 1. Psychosis cases had a lower level of education $\left(\chi^{2}=32.60, p<0.001\right)$, and were more often of non-White ethnicity $\left(\chi^{2}=76.73, p<0.001\right)$ compared with controls, and thus we controlled for these variables in the subsequent analyses. There was no significant difference between psychosis cases and controls in terms of gender $\left(\chi^{2}=2.57, p=0.065\right)$ and age $(t=0.342$, $p=0.733$ ). Total number of childhood adversities experienced was associated with having a 
psychotic disorder $(z=4.97, p<0.001)$, with first-presentation psychosis patients more than twice as likely as controls to report exposure to one (Adjusted OR=2.01, 95\% CI 1.30-3.11, $p=0.002$ ) or multiple (Adjusted $\mathrm{OR}=2.17,95 \%$ CI 1.31-3.61, $p=0.003$ ) childhood adversities.

Table 1 shows the distribution of the COMT Val ${ }^{158}$ Met, AKT1 rs 2494732 , and DRD2 rs 1076560 genotypes in cases and controls along with the findings of the Hardy-Weinberg Equilibrium (HWE) tests. The COMT genotypes were in HWE amongst controls $\left(\chi^{2}=2.881\right.$, $p=0.089)$, however in the cases the HWE was breached $(p=0.034)$. The distribution of the COMT genotypes was similar between psychosis cases and controls and this was confirmed by a non-significant result for Cuzick's non-parametric trend test $(\mathrm{z}=0.46, p=0.645)$. The AKT1 rs2494732 polymorphism allele was in HWE amongst both cases $\left(\chi^{2}=0.525, p=0.468\right)$ and controls $\left(\chi^{2}=0.030, p=0.864\right)$. There was no main association between the $A K T 1$ rs2494732 polymorphism and psychosis in this sample $(z=0.32, p=0.748)$. Similarly, the DRD2 genotypes were in HWE amongst cases $\left(\chi^{2}=0.009, p=0.923\right)$ and controls $\left(\chi^{2}=0.017\right.$, $p=895)$, and there was a non-significant result for Cuzick's non-parametric trend test $(\mathrm{z}=-0.95$, $p=0.341$ ) indicative of no association between DRD2 rs 1076560 and psychosis status in this sample.

\subsection{Gene-environment correlation}

The proportion of participants with each genotype was compared for those with and without a history of childhood adversity (Table 2). There was no significant difference in the number of childhood adversities reported by COMT genotype amongst cases $(\mathrm{z}=1.05$, $p=0.292)$ or controls $(\mathrm{z}=1.07, p=0.283)$. Similarly, no significant gene-environment correlations were found overall between the AKT1 genotype and childhood adversity amongst cases $(\mathrm{z}=-0.96, \mathrm{p}=0.338)$ or controls $(\mathrm{z}=1.50, p=0.134)$, as well as between DRD2 genotype and childhood adversity in cases $(\mathrm{z}=-1.35, \mathrm{p}=0.176)$ or controls $(\mathrm{z}=0.67, p=0.503)$. 


\subsection{Genotype by childhood adversity interaction in psychosis}

Table 3 presents the main effects of the total number of childhood adversities and their interactions with COMT, $A K T 1$ and $D R D 2$ additive genetic models on the presence of psychosis. The total number of adversities was associated with psychosis regardless of COMT, AKT1 and DRD2 genotypes (all $p$ 's<0.05). No significant interactions with childhood adversity were found under an additive genetic model in all the polymorphisms (all $p$ 's $>0.05)$. Additionally, no significant interactions were found for multiple adversities with COMT, AKT1 and DRD2 under dominant or recessive genetic models (Supplementary Table 2).

\section{Discussion}

No main associations between the selected polymorphisms and psychosis case status or childhood adversity were found in this sample. This is in line with previous findings on COMT $\mathrm{Val}^{158}$ Met which have been inconsistent (Glatt et al., 2003) and even a large familybased study found only modest associations between this variant and schizophrenia (Chen et al., 2004b). Moreover, recent meta-analyses concluded that there was no, or at best only weak, evidence of COMT genotype increasing risk for psychosis (Fan et al., 2005; Munafo et al., 2005; Ripke et al., 2013). Our findings on AKT1 rs2494732 polymorphism and psychotic disorder in this sample are in contrast with some previous studies that found an association between this candidate gene and schizophrenia (Bolog et al., 2012; Karege et al., 2012; Norton et al., 2007; Thiselton et al., 2008). Furthermore, despite the DRD2 gene being identified in a recent genome-wide association study (Ripke et al., 2013) as a risk gene for 
schizophrenia, our results did not support this finding in a more broadly defined psychotic disorder sample.

There was, as expected, a main association between total number of adverse childhood experiences and presence of psychotic disorder but this occurred regardless of genotype for the polymorphisms studied. This is in line with our previous paper that showed an association between childhood adversity and psychosis onset, regardless of schizophrenia polygenic risk score (Trotta et al., 2016). However, it is in contrast to previous studies that have shown the greatest impact of stressful events on psychotic symptoms amongst individuals with at least one COMT Val allele compared to those homozygous for the Met allele (Simons et al., 2009; Stefanis et al., 2007), although other studies have found greater sensitivity for the Met/Met genotype (Myin-Germeys et al., 2006; van Winkel et al., 2008a). This discrepancy could be partly due to differences in the demographics of the samples, type of psychotic outcome or intensity of the stressors studied (Simons et al., 2009; van Winkel et al., 2008b) more than the specific alleles.

Disruptions in postnatal rearing conditions can lead to profound and lasting changes in the responsiveness of mesocorticolimbic dopamine neurons to stress in animals (Brake et al, 2004; Hall et al., 1999; Pani et al., 2000) as well as in humans (Collip et al., 2008; Pruessner et al, 2004). According to the social defeat hypothesis, long-term exposure to the experience of social defeat or social exclusion may lead to sensitization of the mesolimbic dopamine system (and/or increased baseline activity of this system) and thereby increase the risk for schizophrenia (Cao et al., 2010; Selten et al., 2013; van Nierop et al., 2014b). Therefore, exposure to childhood adversity might lead to dysfunctional emotional responses (e.g. greater anticipation of threatening events) (Freeman et al., 2013; Bentall et al., 2014) which in turn are associated with an anomalous dopaminergic response (Deutch et al., 1990), 
facilitating the onset of psychotic symptoms (Goto et al., 2007; Kapur, 2003; Kapur et al., 2005).

There was no evidence of genotype by childhood adversity interactions for presence of psychotic disorder. These results are in line with a previous study which found no interaction between COMT Val ${ }^{158}$ Met genotype and childhood maltreatment in predicting schizophreniform disorder at 26 years of age (Caspi et al., 2005). However, previous animal studies have shown an interaction between COMT and maternal care in mice (Zhang et al., 2005). A three-way interaction between the COMT genotype Val alleles, childhood maltreatment, and adolescent cannabis use has also been reported in the etiology of psychotic experiences (Alemany et al., 2013; Vinkers et al., 2013). Similarly, previous studies found an interaction between AKT1 rs2494732 and DRD2 rs1076560 with cannabis use in firstepisode psychosis (Di Forti et al., 2012; van Winkel et al., 2011b; Colizzi et al. 2015a; 2015b). Therefore, it might be that the lack of an interaction effect between COMT, AKT1, DRD2 and childhood adversity on psychosis in the current sample could be due to other environmental factors influencing psychosis case status.

\subsection{Limitations}

It is important to consider the current findings in light of several limitations. The most important consideration in this regard is low a priori probability of interaction and/or low statistical power (Duncan \& Keller, 2011), issues that are more common in candidate gene approaches (Burton et al., 2009). Our results should thus be interpreted with caution. Although these findings need to be replicated in a larger-scale study, we have previously shown in the same sample that DRD2 and $A K T 1$ polymorphisms interact in increasing the risk of psychosis in cannabis users compared to non-users (Colizzi et al., 2015b). Therefore, our negative findings could suggest that other environmental factors might be interacting 
with the dopamine genetic pathway, such as substance use (Di Forti et al., 2012) or stressful life events occurring in adulthood (Beards et al., 2013), to lead to the development of psychosis. Furthermore, this study may have failed to detect an interaction also because of the utilization of retrospective self-report measures (i.e. CECA-Q; Bifulco et al., 2005).

Moreover, this sample was multiethnic. This may be important in light of the differences in allele frequency across the main ethnic groups (African and European origin; Knowler et al., 1988). However, to account for the possibility of population stratification, all analyses were controlled for the potential confounding effect of genetic ancestry to reduce this potential bias in the results. In this sample, one SNP was also in Hardy-Weinberg disequilibrium. As SNPs in Hardy-Weinberg disequilibrium are less powerful, and do not tend to increase false-positive results (Fardo et al., 2009), the reported results are unlikely to be caused by Hardy-Weinberg disequilibrium, especially given the absence of quality control issues (the genotypes were successfully identified at call rates of between $79 \%$ and $85 \%$ ).

We also chose to focus on functionally-relevant candidate genes as we previously found no interaction with childhood adversity and a schizophrenia PRS in relation to psychosis (Trotta et al., 2016). However, this approach also has limitations. One potential way to overcome the limitations from both single candidate gene and PRS studies would be to identify co-expression pathways of risk genes in schizophrenia (Harrison \& Weinberger, 2005). Because genes interact with each other and are co-regulated by a common biological process (e.g., mRNA), the investigation of gene pathways has been argued to have greater biological validity than single gene and PRS approaches (Mitra et al., 2010). For instance, Weighted Gene Co-expression Network Analysis (WGCNA) integrates information related to multiple genes and identifies clusters of co-expressed genes based on similar genetic profiles across individuals (Monaco et al., 2018). Recent findings have, for example, identified a cluster for the DRD2 pathway prefrontal co-expression, which has been found to be 
associated with greater prefrontal activity and working memory impairment in schizophrenia (Pergola et al., 2017). Therefore, the identification of specific molecular pathways could improve the understanding of the genetic factors related with psychotic disorders and should be explored in interaction with childhood adversity and other environmental factors in future studies.

In conclusion, the current study did not provide evidence of an interaction between specific candidate genes and childhood adversity in psychosis onset and, therefore, in this particular sample, the specific genotypes involved in the dopamine pathway did not seem to moderate the effect of adverse childhood experiences on presence of psychotic disorder. 


\section{Acknowledgements}

The authors gratefully acknowledge the help of the GAP and PUMP study teams, all study participants, the South London \& Maudsley Mental Health NHS Foundation Trust, Dr. Paddy Power, consultant psychiatrist, Lambeth Early Onset Psychosis team, the UK National Institute of Health Research (NIHR) Maudsley Biomedical Research Centre, and the Institute of Psychiatry, Psychology \& Neuroscience, King's College London. The work was supported by the Maudsley Charitable Fund and the United Kingdom (UK) National Institute of Health Research (NIHR) Specialist Biomedical Research Centre for Mental Health grant (BRCSLAM). RMM, ASD and VM receive salary support from the NIHR Maudsley BRC. CI is funded by a NARSAD Young Investigator award [22604] from the Brain \& Behavior Research Foundation. HLF was supported by a UK Medical Research Council Population Health Scientist award [G1002366] and an MQ Fellows Award [MQ14F40].

\section{Conflict of interest}

RMM has received honoraria from Janssen, Astra-Zeneca, Lilly, and BMS. ASD has received honoraria from Janssen and Roche Pharmaceuticals. CP has received research funding from Johnson \& Johnson and from a Wellcome-led Consortium that also includes Lundbeck, GlaxoSmithKline and Pfizer, as well as personal consultancy fees from Lundbeck and Eleusis Benefit Corporation. All other authors declare no competing interests.

\section{References}

Alemany, S., Goldberg, X., van Winkel, R., Gastó, C., Peralta, V., Fañanás, L., 2013.

Childhood adversity and psychosis: examining whether the association is due to genetic confounding using a monozygotic twin differences approach. Eur. Psychiatry. 28, 207-212.

Beards, S., Gayer-Anderson, C., Borges, S., Fisher, H.L., Morgan, C., 2013. Life events and psychosis: A review and meta-analysis. Schizophr. Bull. 39 (4), 740-747.

Bebbington, P., Nayani, T., 1995. The Psychosis Screening Questionnaire. Int. J. Methods Psychiatr. Res. 5, 11-20.

Bentall, R.P., de Sousa, P., Varese, F., Wickham, S., Sitko, K., Haarmans, M., Read, J., 2014. From adversity to psychosis: pathways and mechanisms from specific adversities to specific symptoms. Soc. Psychiatry Psychiatr. Epidemiol. 49 (7), 1011-1022.

Bifulco, A., Bernazzani, O., Moran, P.M., Jacobs, C., 2005. The Childhood Experiences of Care and Abuse Questionnaire (CECA.Q) - validation in a community series. Br. J. Clin. Psychol. 44, 563-581. 
Bilder, R.M., Volavka, J., Lachman, H.M., Grace, A.A., 2004. The catechol-Omethyltransferase polymorphism: relations to the tonic-phasic dopamine hypothesis and neuropsychiatric phenotypes. Neuropsychopharmacology. 29 (11), 1943-1961.

Bolog, Z., Kiss, I., Bolcs, K.M., 2012. New schizophrenia loci may converge on the same cellular mechanism: The AKT pathway. Am. J. Psychiatry. 169 (3), 335.

Brake, W.G., Zhang, T.Y., Diorio, J., Meaney, M.J., Gratton, A., 2004. Influence of early postnatal rearing conditions on mesocorticolimbic dopamine and behavioural responses to psychostimulants and stressors in adult rats. Eur. J. Neurosci. 19, 1863-1874.

Bruenig, D., White, M.J., Young, R.M., Voisey, J., 2014. Subclinical psychotic experiences in healthy young adults: associations with stress and genetic predisposition. Genet. Test Mol. Biomarkers. 18 (10), 683-689.

Burton, P.R., Hansell, A.L., Fortier, I., Manolio, T.A., Khoury, M.J., Little, J., Elliott, P., 2009. Size matters: just how big is BIG?: Quantifying realistic sample size requirements for human genome epidemiology. Int. J. Epidemiol. 38 (1), 263-273.

Cao, J.L., Covington III, H.E., Friedman, A.K., Wilkinson, M.B., Walsh, J.J., Cooper, D.C., Nestler, E.J., Han, M.H., 2010. Mesolimbic dopamine neurons in the brain reward circuit mediate susceptibility to social defeat and antidepressant action. J. Neurosci. 30 (49), 16453-16458.

Caspi, A., Moffitt, T.E., Cannon, M., McClay, J., Murray, R., Harrington, H., Taylor, A., Arseneault, L., Williams, B., Braithwaite, A., Poulton, R., Craig, I.W., 2005. Moderation of the effect of adolescent-onset cannabis use on adult psychosis by a functional polymorphism in the catechol-O- methyltransferase gene: longitudinal evidence of a gene X environment interaction. Biol. Psychiatry. 57 (10), 1117-1127.

Chen, J., Lipska, B.K., Halim, N., Ma, Q.D., Matsumoto, M., Melhem, S., Kolachana, B.S., Hyde, T.M., Herman, M.M., Apud, J., Egan, M.F., Kleinman, J.E., Weinberger, D.R., 2004a. Functional analysis of genetic variation in catechol-O-methyltransferase (COMT): effects on mRNA, protein, and enzyme activity in postmortem human brain. Am. J. Hum. Genet. 75, 807-821.

Chen, X., Wang, X., O'Neill, A.F., Walsh, D., Kendler, K.S., 2004b. Variants in the catecholo-methyltransferase (COMT) gene are associated with schizophrenia in Irish high-density families. Mol. Psychiatry. 9 (10), 962-967.

Cheng, R., Juo, S.H., Loth, J.E., Nee, J., Iossifov, I., Blumenthal, R., Sharpe, L., Kanyas, K., Lerer, B., Lilliston, B., Smith, M., Trautman, K., Gilliam, T.C., Endicott, J., Baron, M., 2006. Genome-wide linkage scan in a large bipolar disorder sample from the National Institute of Mental Health genetics initiative suggests putative loci for bipolar disorder, psychosis, suicide, and panic disorder. Mol. Psychiatry. 11 (3), 252-260. 
Colizzi, M., Iyegbe, C., Powell, J., Ursini, G., Porcelli, A., Bonvino, A., Taurisano, P., Romano, R., Masellis, R., Blasi, G., Morgan, C., Aitchison, K., Mondelli, V., Luzi, S., Kolliakou, A., David, A., Murray, R.M., Bertolino, A., Di Forti, M., 2015a. Interaction between functional genetic variation of DRD2 and cannabis use on risk of psychosis. Schizophr Bull. 41 (5), 1171-1182.

Colizzi, M., Iyegbe, C., Powell, J., Blasi, G., Bertolino, A., Murray, R.M., Di Forti, M., 2015b. Interaction between DRD2 and AKT1 genetic variations on risk of psychosis in cannabis users: a case-control study. NPJ Schizophr. 1, 15025.

Collip, D., Myin-Germeys, I., Van Os, J., 2008. Does the concept of "sensitization" provide a plausible mechanism for the putative link between the environment and schizophrenia? Schizophr. Bull. 34 (2), 220-225.

Cuzick, J., 1985. A Wilcoxon-type test for trend. Stat. Med. 4, 87-90.

De Bellis, M.D., Keshavan, M.S., Clark, D.B., Casey, B.J., Giedd, J.N., Boring, A.M., Frustaci, K., Ryan, N.D., 1999. Developmental traumatology part II: brain development. Biol. Psychiatry. 45, 1271-1284.

Deutch, A.Y., Clark, W.A., Roth, R.H., 1990. Prefrontal cortical dopamine depletion enhances the responsiveness of mesolimbic dopamine neurons to stress. Brain. Res. 521 (12), 311-315.

Di Forti, M., Morgan, C., Dazzan, P., Pariante, C., Mondelli, V., Marques, T.R., Handley, R., Luzi, S., Russo, M., Paparelli, A., Butt, A., Stilo, S.A., Wiffen, B., Powell, J., Murray, R.M., 2009. High-potency cannabis and the risk of psychosis. Br. J. Psychiatry. 195 (6), 488-491.

Di Forti, M., Marconi, A., Carra, E., Fraietta, S., Trotta, A., Bonomo, M., Bianconi, F., Gardner-Sood, P., O'Connor, J., Russo, M., Stilo, S.A., Marques, T.R., Mondelli, V., Dazzan, P., Pariante, C., David, A.S., Gaughran, F., Atakan, Z., Iyegbe, C., Powell, J., Morgan, C., Lynskey, M., Murray, R.M., 2015. Proportion of patients in south London with first-episode psychosis attributable to use of high potency cannabis: a case-control study. Lancet Psychiatry. 2 (3), 233-238.

Duncan, L.E., Keller, M.C., 2011. A critical review of the first 10 years of candidate geneby-environment interaction research in psychiatry. Am. J. Psychiatry. 168, 1041-1049.

Egan, M.F., Goldberg, T.E., Kolachana, B.S., Callicott, J.H., Mazzanti, C.M., Straub, R.E., Goldman, D., Weinberger, D.R., 2001. Effect of COMT Val108/158 Met genotype on frontal lobe function and risk for schizophrenia. ProcNatl. Acad. Sci. U. S. A. 98, 69176922. 
Egerton, A., Valmaggia, L.R., Howes, O.D., Day, F., Chaddock, C.A., Allen, P., WintonBrown, T.T., Bloomfield, M.A., Bhattacharyya, S., Chilcott, J., Lappin, J.M., Murray, R.M., McGuire, P., (2016). Adversity in childhood linked to elevated striatal dopamine function in adulthood. Schizophr Res. 176 (2-3), 171-176.

Falush, D., Stephens, M., Pritchard, J.K., 2003. Inference of population structure using multilocus genotype data: Linked loci and correlated allele frequencies. Genetics. 164, 1567-1587.

Fan, J.B., Zhang, C.S., Gu, N.F., Li, X.W., Sun, W.W., Wang, H.Y., Feng, G.Y., St Clair, D., He, L., 2005. Catechol-O-methyltransferase gene Val/Met functional polymorphism and risk of schizophrenia: a large-scale association study plus meta-analysis. Biol. Psychiatry. $57,139-144$.

Fardo, D.W., Becker, K.D., Bertram, L., Tanzi, R.E., Lange, C., 2009. Recovering unused information in genome-wide association studies: the benefit of analysing SNPs out of Hardy-Weinberg equilibrium. Eur. J. Hum. Genet. 17, 1676-1682.

Fisher, H.L., Craig, T.K., Fearon, P., Morgan, K., Dazzan, P., Lappin, J., Hutchinson, G., Doody, G.A., Jones, P.B., McGuffin, P., Murray, R.M., Leff, J., Morgan, C., 2011. Reliability and comparability of psychosis patients' retrospective reports of childhood abuse. Schizophr. Bull. 37, 546-553.

Freeman, D., Startup, H., Dunn, G., Černis, E., Wingham, G., Pugh, K., Cordwell, J., Kingdon, D., 2013. The interaction of affective with psychotic processes: a test of the effects of worrying on working memory, jumping to conclusions, and anomalies of experience in patients with persecutory delusions. J. Psychiatr. Res. 47 (12), 1837 -1842.

Freyberg, Z., Ferrando, S. J., Javitch, J.A., 2010. Roles of the Akt/GSK-3 and Wnt signalling pathways in schizophrenia and antipsychotic drug action. Am. J. Psychiatry. 167 (4), 388396.

Garris, P.A., Collins, L.B., Jones, S.R., Wightman, R.M., 1993. Evoked extracellular dopamine in vivo in the medial prefrontal cortex. J. Neurochem. 61 (2), 637- 647.

Gerra, G., Leonardi, C., Cortese, E., Zaimovic, A., Dell'agnello, G., Manfredini, M., Somaini, L., Petracca, F., Caretti, V., Raggi, M.A., Donnini, C., 2009. Childhood neglect and parental care perception in cocaine addicts: Relation with psychiatric symptoms and biological correlates. Neurosci. Biobehav. Rev. 33 (4), 601-610.

Glatt, S.J., Faraone, S.V., Tsuang, M.T., 2003. Association between a functional catechol-Omethyltransferase gene polymorphism and schizophrenia: meta-analysis of case-control and family-based studies. Am. J. Psychiatry. 160, 469-476.

Goto, Y., Otani, S., Grace, A.A., 2007. The Yin and Yang of dopamine release: a new perspective. Neuropharmacology. 53 (5), 583-587.Hall, F.S., Wilkinson, L.S., Humby, T., 
Robbins, T.W., 1999. Maternal deprivation of neonatal rats produces enduring changes in dopamine function. Synapse. 32, 37-43.

Harrison, P.J, Weinberger, D.R., 2005. Schizophrenia genes, gene expression, and neuropathology: on the matter of their convergence. Mol Psychiatry. 10 (1), 40-68.

Heim, C., Newport, D., Heit, S., Graham, Y.P., Wilcox, M., Bonsall, R., Miller, A.H., Nemeroff, C.B., 2000. Pituitary-adrenal and autonomic responses to stress in women after sexual and physical abuse in childhood. J.A.M.A. 284, 592- 597.

Henquet, C., Rosa, A., Delespaul, P., Papiol, S., Fananás, L., van Os, J., Myin- Germeys, I., 2009. COMT ValMet moderation of cannabis-induced psychosis: a momentary assessment study of 'switching on' hallucinations in the flow of daily life. Acta Psychiatr. Scand. 119, 156160.

Howes, O.D., McCutcheon, R., Owen, M.J., Murray, R.M., 2017. The role of genes, stress, and dopamine in the development of schizophrenia. Biol Psychiatry. 81 (1), 9-20.

Howes, O.D., McDonald, C., Cannon, M., Arseneault, L., Boydell, J., Murray, R.M., 2004. Pathways to schizophrenia: the impact of environmental factors. Int $\mathrm{J}$ Neuropsychopharmacol. 7 (Suppl 1), S7-S13.

Howes, O.D., Montgomery, A.J., Asselin, M.C., Murray, R.M., Valli, I., Tabraham, P., Bramon-Bosch, E., Valmaggia, L., Johns, L., Broome, M., McGuire, P.K., Grasby, P.M., 2009. Elevated striatal dopamine function linked to prodromal signs of schizophrenia. Arch. Gen. Psychiatry. 66 (1), 13-20.

Kapur, S., Zipursky, R.B., Remington, G., 1999. Clinical and theoretical implications of 5HT2 and D2 receptor occupancy of clozapine, risperidone, and olanzapine in schizophrenia. Am. J. Psychiatry. 156, 286-293.

Kapur, S., 2003. Psychosis as a state of aberrant salience: a framework linking biology, phenomenology, and pharmacology in schizophrenia. Am, J. Psychiatry. 160, 13-24.

Kapur, S., Mizrahi, R., Li, M., 2005. From dopamine to salience to psychosis-- linking biology, pharmacology and phenomenology of psychosis. Schizophr. Res. 79 (1), 59-68.

Karege, F., Meary, A., Perroud, N., Jamain, S., Leboyer, M., Ballmann, E., Fernandez, R., Malafosse, A., Schürhoff, F., 2012. Genetic overlap between schizophrenia and bipolar disorder: A study with AKT1 gene variants and clinical phenotypes. Schizophr. Res. 135, $8-14$.

Knol, M.J., van der Tweel, I., Grobbee, D.E., Numans, M.E., Geerlings, M.I., 2007. Estimating interaction on an additive scale between continuous determinants in a logistic regression model. Int. J. Epidemiol. 36, 1111-1118. 
Knowler, W.C., Williams, R.C., Pettitt, D.J., Steinberg, A.G., 1988. Gm3,5,13,14 and type 2 diabetes mellitus: an association in American Indians with genetic admixture. Am. J. Hum. Genet. 43 (4), 520-526.

Li, T., Sham, P.C., Vallada, H., Xie, T., Tang, X., Murray, R.M., Liu, X., Collier, D.A., 1996. Preferential transmission of the high activity allele of COMT in schizophrenia. Psychiatr. Genet. 6 (3), 131-133.

Mannisto, P. T., Kaakkola S., 1999. Catechol-O-methyltransferase (COMT): biochemistry, molecular biology, pharmacology, and clinical efficacy of the new selective COMT inhibitors. Pharmacol. Rev. 51 (4), 593-628.

Mathur, A., Law M.H., Megson, I.L., Shaw, D.J., Wei, J., 2010. Genetic association of the AKT1 gene with schizophrenia in a British population. Psychiatr. Genet. 20 (3), 118-122.

Mitra, K., Carvunis, A.R., Ramesh, S.K., Ideker, T. 2013. Integrative approaches for finding modular structure in biological networks. Nat Rev Genet. 14 (10), 719-732.

Monaco, A., Monda, A., Amoroso, N., Bertolino, A., Blasi, G., Di Carlo, P., Papalino, M., Pergola, G., Tangaro, S., Bellotti, R., 2018. A complex network approach reveals a pivotal substructure of genes linked to schizophrenia. PLoS One. 13 (1), e0190110.

Moore, H., West, A.R., Grace, A.A., 1999. The regulation of forebrain dopamine transmission: relevance to the pathophysiology and psychopathology of schizophrenia. Biol. Psychiatry. 46, 40-55.

Morgan, C., Gayer-Anderson, C. (2016). Childhood adversities and psychosis: evidence, challenges, implications. World Psychiatry.15 (2), 93-102.

Munafo, M.R., Bowes, L., Clark, T.G., Flint, J., 2005. Lack of association of the COMT (Val158/108 Met) gene and schizophrenia: a meta-analysis of case- control studies. Mol. Psychiatry. 10, 765-770.

Myin-Germeys, I., Henquet, C., Rosa, A., Papiol, S., Fananas, L., van Os, J., 2006. A functional polymorphism in the COMT gene moderates psychotic reactivity to stress. Schizophr. Res. 81, 221.

Norton, N., Williams, H.J., Dwyer, S., Carroll, L., Peirce, T., Moskvina, V., Segurado, R., Nikolov, I., Williams, N.M., Ikeda, M., Iwata, N., Owen, M.J., O'Donovan, M.C., 2007. Association analysis of AKT1 and schizophrenia in a UK case control sample. Schizophr. Res. 93 (1-3), 58-65.

Pani, L., Porcella, A., Gessa, G.L., 2000. The role of stress in the pathophysiology of the dopaminergic system. Mol. Psychiatry. 5, 14-21.

Peerbooms, O., Rutten, B.P., Collip, D., Lardinois, M., Lataster, T., Thewissen, V., Rad, S.M., Drukker, M., Kenis, G., van Os, J., Myin-Germeys, I., van Winkel, R., 2012. Evidence that interactive effects of COMT and MTHFR moderate psychotic response to environmental stress. Acta Psychiatr. Scand. 125 (3), 247-256. 
Pergola, G., Di Carlo, P., D'Ambrosio, E., Gelao, B., Fazio, L., Papalino, M., Monda, A., Scozia, G., Pietrangelo, B., Attrotto, M., Apud, J.A., Chen, Q., Mattay, V.S., Rampino, A., Caforio, G., Weinberger, D.R., Blasi, G., Bertolino, A., 2017. DRD2 co-expression network and a related polygenic index predict imaging, behavioral and clinical phenotypes linked to schizophrenia. Transl. Psychiatry. 7 (1), e1006.

Pruessner, J.C., Champagne, F., Meaney, M.J., Dagher, A., 2004. Dopamine release in response to a psychological stress in humans and its relationship to early life maternal care: a positron emission tomography study using [11C]raclopride. J. Neurosci. 24, 28252831.

Ripke, S., O’Dushlaine, C., Chambert, K., Moran, J.L., Kähler, A.K., Akterin, S., Bergen, S.E., Collins, A.L., Crowley, J.J., Fromer, M., Kim, Y., Lee, S.H., Magnusson, P.K., Sanchez, N., Stahl, E.A., Williams, S., Wray, N.R., Xia, K., Bettella, F., Borglum, A.D., Bulik-Sullivan, B.K., Cormican, P., Craddock, N., de Leeuw, C., Durmishi, N., Gill, M., Golimbet, V., Hamshere, M.L., Holmans, P., Hougaard, D.M., Kendler, K.S., Lin, K., Morris, D.W., Mors, O., Mortensen, P.B., Neale, B.M., O'Neill, F.A., Owen, M.J., Milovancevic, M.P., Posthuma, D., Powell, J., Richards, A.L., Riley, B.P., Ruderfer, D., Rujescu, D., Sigurdsson, E., Silagadze, T., Smit, A.B., Stefansson, H., Steinberg, S., Suvisaari, J., Tosato, S., Verhage, M., Walters, J.T.; Multicenter Genetic Studies of Schizophrenia Consortium, Levinson, D.F., Gejman, P.V., Kendler, K.S., Laurent, C., Mowry, B.J., O'Donovan, M.C., Owen, M.J., Pulver, A.E., Riley, B.P., Schwab, S.G., Wildenauer, D.B., Dudbridge, F., Holmans, P., Shi, J., Albus, M., Alexander, M., Campion, D., Cohen, D., Dikeos, D., Duan, J., Eichhammer, P., Godard, S., Hansen, M., Lerer, F.B., Liang, K.Y., Maier, W., Mallet, J., Nertney, D.A., Nestadt, G., Norton, N., O'Neill, F.A., Papadimitriou, G.N., Ribble, R., Sanders, A.R., Silverman, J.M., Walsh, D., Williams, N.M., Wormley, B.; Psychosis Endophenotypes International Consortium, Arranz, M.J., Bakker, S., Bender, S., Bramon, E., Collier, D., Crespo-Facorro, B., Hall, J., Iyegbe, C., Jablensky, A., Kahn, R.S., Kalaydjieva, L., Lawrie, S., Lewis, C.M., Lin, K., Linszen, D.H., Mata, I., McIntosh, A., Murray, R.M., Ophoff, R.A., Powell, J., Rujescu, D., Van Os, J., Walshe, M., Weisbrod, M., Wiersma, D.; Wellcome Trust Case Control Consortium 2, Donnelly, P., Barroso, I., Blackwell, J.M., Bramon, E., Brown, M.A., Casas, J.P., Corvin, A.P., Deloukas, P., Duncanson, A., Jankowski, J., Markus, H.S., Mathew, C.G., Palmer, C.N., Plomin, R., Rautanen, A., Sawcer, S.J., Trembath, R.C., Viswanathan, A.C., Wood, N.W., Spencer, C.C., Band, G., Bellenguez, C., Freeman, C., Hellenthal, G., Giannoulatou, E., Pirinen, M., Pearson, R.D., Strange, A., Su, Z., Vukcevic, D., Donnelly, P., Langford, C., Hunt, S.E., Edkins, S., Gwilliam, R., Blackburn, H., Bumpstead, S.J., Dronov, S., Gillman, M., Gray, E., Hammond, N., Jayakumar, A., McCann, O.T., Liddle, J., Potter, S.C., Ravindrarajah, R., Ricketts, M., Tashakkori- Ghanbaria, A., Waller, M.J., Weston, P., Widaa, S., Whittaker, P., Barroso, I., Deloukas, P., Mathew, C.G., Blackwell, J.M., Brown, M.A., Corvin, A.P., McCarthy, M.I., Spencer, C.C., Bramon, E., Corvin, A.P., O'Donovan, M.C., Stefansson, K., Scolnick, E., Purcell, S., McCarroll, S.A., Sklar, P., Hultman, C.M., Sullivan, P.F., 2013. Genome-wide association analysis identifies 13 new risk loci for schizophrenia. Nat. Gen. 45, 1150-1159.

Savitz, J., van der Merwe, L., Newman, T.K., Stein, D.J., Ramesar, R., 2010. Catechol-omethyltransferase genotype and childhood trauma may interact to impact schizotypal personality traits. Behav. Genet. 40, 415-423. 
Selten, J.P., van der Ven, E., Rutten, B.P., Cantor-Graae, E., 2013. The social defeat hypothesis of schizophrenia: an update. Schizophr. Bull. 39 (6), 1180-1186.

Shevlin, M., Houston, J.E., Dorahy, M.J., Adamson, G. (2008). Cumulative traumas and psychosis: an analysis of the national comorbidity survey and the British Psychiatric Morbidity Survey. Schizophr Bull. 34 (1), 193-199.

Simons, C., Wichers, M., Derom, C., Thiery, E., Myin-Germeys, I., Krabbendam, L., van Os, J., 2009. Subtle gene-environment interactions driving paranoia in daily life. Genes Brain. Behav. 8 (1), 5-12.

Smith, N., Lam, D., Bifulco, A., Checkley, S., 2002. Childhood Experience of Care and Abuse Questionnaire (CECA.Q): validation of a screening instrument for childhood adversity in clinical populations. Soc. Psychiatry Psychiatr. Epidemiol. 37, 572-579.

Spitzer, M., Hermle, L., 1995. From degeneration to anticipation. Systematic and historical scientific aspects of the genetics of neuropsychiatric diseases. Nervenarzt. 66 (3), 187-196.

Stefanis, N.C., Henquet, C., Avramopoulos, D., Smyrnis, N., Evdokimidis, I., Evdokimidis, I., Myin-Germeys, I., Stefanis, C.N, Van Os, J., 2007. COMT Val158Met moderation of stress-induced psychosis. Psychol. Med. 37 (11), 1651-1656.

Thiselton, D.L., Vladimirov, V.I., Kuo, P.H., McClay, J., Wormley, B., Fanous, A., O'Neill, F.A., Walsh, D., Van den Oord, E.J., Kendler, K.S., Riley, B.P., 2008. AKT1 is associated with schizophrenia across multiple symptom dimensions in the Irish study of high density schizophrenia families. Biol. Psychiatry. 63 (5), 449-457.

Trotta, A., Di Forti, M., Iyegbe, C., Green, P., Dazzan, P., Mondelli, V., Morgan, D., Murray R., Fisher, H.L., 2015. Familial risk and childhood adversity interplay in the onset of psychosis. BJPsych Open. 1, 6-13.

Trotta, A., Iyegbe, C., Di Forti, M., Sham, P.C., Campbell, D.D., Cherny, S.S, Mondelli, V., Murray, R.M., Vassos, E., Fisher, H.L., 2016. Interplay between Schizophrenia Polygenic Risk Scores and Childhood Adversity in First-Presentation Psychotic Disorder: A Pilot Study. PLoS One. 11(9), e0163319.

Tunbridge, E.M., Harrison, P.J., Weinberger, D.R., 2006. Catechol-o- methyltransferase, cognition, and psychosis: Val158Met and beyond. Biol. Psychiatry. 60, 141-151.

van Nierop, M., van Os, J., Gunther, N., van Zelst, C., de Graaf, R., ten Have, M., van Dorsselaer, S., Bak, M., Myin-Germeys, I., van Winkel, R., 2014. Does social defeat mediate the association between childhood trauma and psychosis? Evidence from the NEMESIS-2 Study. Acta Psychiatr. Scand. 129, 467-476.

van Winkel, R., Genetic Risk and Outcome of Psychosis (GROUP) Investigators, 2011a. Family-based analysis of genetic variation underlying psychosis- inducing effects of cannabis: sibling analysis and proband follow-up. Arch. Gen. Psychiatry. 68 (2), 148-157. 
van Winkel, R., Henquet, C., Rosa, A., Papiol, S., Fananás, L., De Hert, M., Peuskens, J., van Os, J., Myin-Germeys, I., 2008a. Evidence that the COMT (Val158Met) polymorphism moderates sensitivity to stress in psychosis: an experience sampling study. Am. J. Med. Genet. B. Neuropsychiatr. Genet. 147B (1), 10-17.

van Winkel, R., Stefanis, N.C., Myin-Germeys, I., 2008b. Psychosocial stress and psychosis. A review of the neurobiological mechanisms and the evidence for gene-stress interaction. Schizophr. Bull. 34 (6), 1095-1105.

van Winkel, R., van Beveren, N.J., Simons, C., 2011b. Genetic Risk and Outcome of Psychosis (GROUP) Investigators: AKT1 moderation of cannabis induced cognitive alterations in psychotic disorder. Neuropsychopharmacology. 36, 2529-2537.

Vinkers, C.H., Van Gastel, W.A., Schubart, C.D., Van Eijk, K.R., Luykx, J.J., Van Winkel, R., Joëls, M., Ophoff, R.A., Boks, M.P.; Genetic Risk and OUtcome of Psychosis (GROUP) Investigators, Bruggeman, R., Cahn, W., de Haan, L., Kahn, R.S., Meijer, C.J., Myin-Germeys, I., van Os, J., Wiersma, D., 2013. The effect of childhood maltreatment and cannabis use on adult psychotic symptoms is modified by the COMT Val158Met polymorphism. Schizophr. Res. 150 (1), 303-311.

Wacholder, S., 1986. Binomial regression in GLIM: estimating risk ratios and risk differences. Am. J. Epidemiol. 123, 174-184.

Walker, E., Diforio, D., 1997. Schizophrenia: a neural diathesis-stress model. Psychol. Rev. 104 (4), 667-685.

Walker, E., Mittal, V., Tessner, K., 2008. Stress and the hypothalamic pituitary adrenal axis in the developmental course of schizophrenia. Annu. Rev. Clin. Psychol. 4, 189-216.

Weinshilboum, R.M., Otterness, D.M., Szumlanski, C.L., 1999. Methylation pharmacogenetics: catechol-o-methyltransferase, thiopurine methyltransferase, and histamine n-methyltransferase. Annu. Rev. Pharmacol. Toxicol. 39, 19-52.

Wellcome Trust Case Control Consortium, 2007. Genome-wide association study of 14,000 cases of seven common diseases and 3,000 shared controls. Nature. 447, 661-678.

Winqvist, R., Lundstrom, K., Salminen, M., Laatikainen, M., Ulmanen, I., 1991. Mapping of human catechol-O-methyltransferase gene to 22q11.2 and detection of a frequent RFLP with BglI. Cytogenet. Cell. Genet. 59, 253-257.

World Health Organisation, 1992. The ICD-10 Classification of Mental and Behavioural Disorders: Clinical Descriptions and Diagnostic Guidelines. World Health Organisation, Geneva.

Zhang, T.Y., Chretien, P., Meaney, M.J., Gratton, A., 2005. Influence of naturally occurring variations in maternal care on prepulse inhibition of acoustic startle and the medial prefrontal cortical dopamine response to stress in adult rats. J. Neurosci. 25 (6), 1493-1502. 
Zhang, Y., Bertolino, A., Fazio, L., Blasi, G., Rampino, A., Romano, R., Lee, M.L., Xiao, T., Papp, A., Wang, D., Sadée, W., 2007. Polymorphisms in human dopamine D2 receptor gene affect gene expression, splicing, and neuronal activity during working memory. Proc Natl Acad Sci USA. 104, 20552-20557. 


\section{Table 1}

Hardy-Weinberg Equilibrium results for COMT, AKT1 and DRD2 genotypes in psychosis cases and unaffected controls

\begin{tabular}{|c|c|c|}
\hline Genotype & $\begin{array}{l}\text { Cases } \\
n(\%)\end{array}$ & $\begin{array}{c}\text { Controls } \\
n(\%)\end{array}$ \\
\hline \multicolumn{3}{|c|}{ COMT Val ${ }^{158} \mathrm{Met}$} \\
\hline $\mathrm{Val} / \mathrm{Val}$ & $96(38.4)$ & $74(36.8)$ \\
\hline $\mathrm{Val} / \mathrm{Met}$ & $130(52)$ & $105(52.2)$ \\
\hline Met/Met & $24(9.6)$ & $22(10.9)$ \\
\hline$H W E$ & $X^{2}=4.493, p=0.034$ & $X^{2}=2.881, p=0.089$ \\
\hline \multicolumn{3}{|c|}{ AKT1 rs 2494732} \\
\hline$C / C$ & $54(22)$ & $43(22.5)$ \\
\hline$C / T$ & $128(52.2)$ & $94(49.2)$ \\
\hline$T / T$ & $63(25.7)$ & $54(28.3)$ \\
\hline$H W E$ & $X^{2}=0.525, p=0.468$ & $X^{2}=0.030, p=0.864$ \\
\hline \multicolumn{3}{|c|}{ DRD2 rs1076560 } \\
\hline$T / T$ & $3(1.2)$ & $3(1.5)$ \\
\hline$G / T$ & $47(19.1)$ & 44 (22.6) \\
\hline$G / G$ & $196(79.7)$ & $148(75.9)$ \\
\hline$H W E$ & $X^{2}=0.009, p=0.923$ & $X^{2}=0.017, p=0.895$ \\
\hline
\end{tabular}

HWE, Hardy-Weinberg Equilibrium. Met, methionine. Val, valine. 
Table 2

Distribution of COMT, AKT1 and DRD2 genotypes by history of childhood adversity in psychosis cases and unaffected controls

\begin{tabular}{|c|c|c|c|c|c|c|c|c|c|c|}
\hline 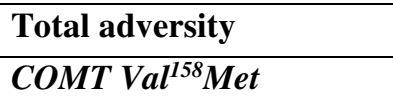 & \multicolumn{3}{|c|}{ Cases } & \multicolumn{7}{|c|}{ Controls } \\
\hline COMT $\mathrm{Val}^{158} \mathrm{Met}$ & $\begin{array}{c}\text { Val/Val } \\
n(\%)\end{array}$ & $\begin{array}{c}\text { Val/Met } \\
n(\%)\end{array}$ & $\begin{array}{c}\text { Met/Met } \\
n(\%)\end{array}$ & $\begin{array}{c}\mathbf{Z} \\
1.05\end{array}$ & $\begin{array}{c}\boldsymbol{P} \\
0.292\end{array}$ & $\begin{array}{c}\text { Val/Val } \\
n(\%)\end{array}$ & $\begin{array}{c}\text { Val/Met } \\
n(\%)\end{array}$ & $\begin{array}{c}\text { Met/Met } \\
n(\%)\end{array}$ & $\begin{array}{c}\mathbf{Z} \\
1.07\end{array}$ & $\begin{array}{c}\boldsymbol{P} \\
0.283\end{array}$ \\
\hline 2 or more adversities & $30(40.5)$ & $37(50.0)$ & $7(9.5)$ & & & $14(40.0)$ & $20(57.1)$ & $1(2.9)$ & & \\
\hline 1 & $42(38.5)$ & $61(56.0)$ & $6(5.5)$ & & & $23(37.1)$ & $32(51.6)$ & $7(11.3)$ & & \\
\hline 0 & $24(35.8)$ & $32(47.8)$ & $11(16.4)$ & & & $37(35.6)$ & $53(51.0)$ & $14(13.4)$ & & \\
\hline AKT1 rs2494732 & $\begin{array}{c}C / C \\
n(\%)\end{array}$ & $\begin{array}{c}C / T \\
n(\%)\end{array}$ & $\begin{array}{c}T / T \\
n(\%)\end{array}$ & & & $\begin{array}{c}C / C \\
n(\%)\end{array}$ & $\begin{array}{c}C / T \\
n(\%)\end{array}$ & $\begin{array}{c}T / T \\
n(\%)\end{array}$ & & \\
\hline & & & & -0.96 & 0.338 & & & & 1.50 & 0.134 \\
\hline 2 or more adversities & $14(19.2)$ & $37(50.7)$ & $14(30.1)$ & & & $5(14.7)$ & $12(35.3)$ & $17(50.0)$ & & \\
\hline 1 & $24(22.2)$ & $59(54.6)$ & $25(23.2)$ & & & $10(16.4)$ & $28(45.9)$ & $23(37.7)$ & & \\
\hline 0 & $16(25.0)$ & $32(50.0)$ & $16(25.0)$ & & & $6(6.2)$ & $47(49.0)$ & $43(44.8)$ & & \\
\hline DRD2 rs1076560 & $\begin{array}{c}T / T \\
n(\%)\end{array}$ & $\begin{array}{c}G / T \\
n(\%)\end{array}$ & $\begin{array}{c}G / G \\
n(\%)\end{array}$ & & & $\begin{array}{c}T / T \\
n(\%)\end{array}$ & $\begin{array}{c}G / T \\
n(\%)\end{array}$ & $\begin{array}{c}G / G \\
n(\%)\end{array}$ & & \\
\hline & & & & -1.35 & 0.176 & & & & 0.67 & 0.503 \\
\hline 2 or more adversities & $1(1.3)$ & $13(17.6)$ & $60(81.1)$ & & & $1(2.9)$ & 7 (20.6) & $26(76.5)$ & & \\
\hline 1 & $0(0.0)$ & $18(16.7)$ & $90(83.3)$ & & & $1(1.7)$ & $16(26.2)$ & $44(72.1)$ & & \\
\hline 0 & $2(3.1)$ & $16(25.0)$ & $46(71.9)$ & & & $1(1.0)$ & $21(21.0)$ & $78(78.0)$ & & \\
\hline
\end{tabular}

Met, methionine. Val, valine. 
Table 3

Main associations and additive interactions between total childhood adversities, COMT Val158Met, AKT1 rs2494732, and DRD2 rs1076560 genotypes on the presence of psychotic disorder

\begin{tabular}{|c|c|c|c|c|c|c|}
\hline Total childhood adversity & Unadjusted RD & $95 \% \mathrm{CI}$ & $P$ value & Adjusted RD* & $95 \% \mathrm{CI}$ & $P$ value \\
\hline \multicolumn{7}{|l|}{ COMT Val ${ }^{158} \mathrm{Met}$} \\
\hline Overall sample $(\mathrm{n}=451)$ & 0.14 & $0.08-0.19$ & $<0.001$ & 0.09 & $0.03-0.15$ & 0.003 \\
\hline Additive GxE interaction & -0.02 & $-0.11-0.06$ & 0.614 & -0.03 & $-0.09-0.04$ & 0.390 \\
\hline \multicolumn{7}{|l|}{ AKT1 rs2494732 } \\
\hline Overall sample $(n=436)$ & 0.13 & $0.07-0.19$ & $<0.001$ & 0.14 & $0.08-0.19$ & $<0.001$ \\
\hline \multicolumn{7}{|l|}{ DRD2 rs 1076560} \\
\hline Overall sample $(\mathrm{n}=441)$ & 0.13 & $0.08-0.19$ & $<0.001$ & 0.09 & $0.03-0.15$ & 0.003 \\
\hline Additive GxE interaction & -0.06 & $0.09-0.22$ & 0.340 & -0.05 & $-0.18-0.07$ & 0.384 \\
\hline
\end{tabular}

